\title{
AMODIAQUINE-ASSOCIATED ADVERSE EFFECTS AFTER INADVER- TENT OVERDOSE AND AFTER A STANDARD THERAPEUTIC DOSE
}

\author{
G. O. ADJEI ${ }^{1,3}$, B. Q. GOKA ${ }^{2}$, O. P. RODRIGUES ${ }^{2}$, L. C. G. HOEGBERG ${ }^{3}$, M. ALIFRANGIS ${ }^{3}$, J. \\ A.L. KURTZHALS ${ }^{3}$ \\ ${ }^{1}$ Centre for Tropical Clinical Pharmacology \& Therapeutics and ${ }^{2}$ Department of Child Health, University of \\ Ghana Medical School, College of Health Sciences, Accra, Ghana; ${ }^{3}$ Centre for Medical Parasitology at De- \\ partment of Clinical Microbiology and Department of Infectious Diseases, Copenhagen University Hospital \\ (Rigshospitalet), and at Department of International Health, Immunology and Microbiology, University of \\ Copenhagen, Denmark
}

\author{
Author for correspondence: Dr. George Obeng Adjei \\ E-mail: goadjei@yahoo.com
}

\author{
Conflict of interest: None declared
}

\section{SUMMARY}

A case of an acute dystonic reaction in a child presumptively treated for malaria with amodiaquine, and a case of persistent asymptomatic bradycardia in another child with mild pulmonary stenosis treated with a standard dose of amodiaquine for parasitologically confirmed uncomplicated malaria, is reported. Both subjects were homozygous for the wild type allele of cytochrome P450 2C8, the main enzyme responsible for amodiaquine metabolism. In both subjects, plasma concentrations of N-desethylamodiaquine and N-bisdesethylamodiaquine, the main metabolites of amodiaquine, were normal. No other drugs were detectable in the plasma of these two subjects after further toxicological screening. These observations, which suggest altered metabolism in the subject with an acute dystonic reaction, support the assertion that amodiaquine-associated dystonia is an idiosyncratic reaction. However, the occurrence of bradycardia after a standard dose of amodiaquine, which coincided with the time of expected peak concentrations of the active metabolite of amodiaquine, suggests a direct drug effect. These less reported adverse effects are likely to increase in parallel with the increased use of amodiaquine as a partner drug for combination therapy of malaria in Ghana. Further studies aimed at elucidating the mechanisms underlying these effects are, therefore, required.

Key words: Amodiaquine, malaria, children, adverse effects, Ghana

\section{INTRODUCTION}

Amodiaquine is a 4-aminoquinoline, which was widely used in the past for both prophylaxis and treatment of malaria. It was withdrawn from use because of fatal side effects, notably agranulocytosis and hepatitis, which occurred mainly in non-immune adults taking the drug for prophylaxis. ${ }^{1,2}$ After oral administration, amodiaquine is rapidly metabolized to $\mathrm{N}$ desethylamodiaquine (DEAQ), the main metabolite responsible for the pharmacological effects of the drug, as well as other metabolites, such as $\mathrm{N}$ bisdesethylamodiaquine (bis-DEAQ) and hydroxylamodiaquine. $^{3}$ The main enzyme responsible for the conversion of amodiaquine to DEAQ is CYP2C8, a polymorphic isoform of hepatic cytochrome p450 2C8, whose gene is located on chromosome 10q 24. Amodiaquine-associated dystonic reaction was first reported from Nigeria in 1976. ${ }^{4}$ Since then, there has been a paucity of similar reports in the published literature until recently, when a series of such cases were reported from Cote d'Ivoire (in 2004) ${ }^{5}$ and from Ghana (in 2005). ${ }^{6}$

The mechanism underlying the well-known side effects of amodiaquine (agranulocytosis and hepatitis) is direct toxicity $^{7}$, or immune-mediated hypersensitivity. ${ }^{8}$ The mechanism underlying the less-described side effects of amodiaquine, such as dystonia, however, has not been elucidated. The reason for the lack of evidence on underlying mechanisms for these amodiaquineassociated adverse effects, other than agranulocytosis and hepatitis, may be due in part, to lack of data on drug concentration profiles from previous studies, as well as lack of data on expression profiles of genes coding for enzymes responsible for amodiaquine metabolism.

In this report, two cases of the less-described adverse effects of amodiaquine, acute dystonic reaction in a child presumptively treated with what was reported to be more than several-fold the recommended dose of amodiaquine, and persistent asymptomatic bradycardia in another child with parasitologically-confirmed un- 
complicated malaria treated with a standard dose of amodiaquine, and who was subsequently found to have mild pulmonary stenosis, are presented. These observations are discussed with reference to possible underlying mechanisms.

\section{Case 1}

The subject was a three year old, $11.2 \mathrm{~kg}$ female referred to Korle Bu Teaching Hospital (KBTH), Accra, with a four-hour history of "restlessness, abnormal behaviour and inability to stand or walk". The patient had been seen three days earlier at a polyclinic in Accra with complaints of fever, anorexia and lethargy, for which she was given a three-day course of amodiaquine (Enoquine ${ }^{\circledR}$, $50 \mathrm{mg} / 5 \mathrm{ml}$, Ernest Chemists, Ghana) to be taken at home. The mother reported administering three teaspoonfuls (approximately $150 \mathrm{mg}$ ) of the drug, three times a day, (instead of once daily), for a total of three days.

The child was seen at the Emergency Room of the Department of Child Health, KBTH, with an axillary temperature of $38.2^{\circ} \mathrm{C}$, inability to respond to verbal requests, an upward moving gaze, protruded tongue, excessive salivation, and increased muscle tone. A diagnosis of an acute dystonic reaction probably due to amodiaquine was made.

The peripheral blood film was negative for malaria parasites; haemoglobin was $7.9 \mathrm{~g} / \mathrm{dl}$; total white blood cell count was $7.5 \times 10^{9} / \mathrm{L}$, with neutrophil differential $61.4 \%$; and platelet count was $92 \times 10^{9} / \mathrm{L}$. Blood urea, serum electrolytes and creatinine levels were normal. The plasma DEAQ concentration measured by a reversed phase High Performance Liquid Chromatography (HPLC) was $153 \mathrm{ng} / \mathrm{ml}$ on presentation, and 110 $\mathrm{ng} / \mathrm{ml}$ three days later. A comparison of the ultraviolet (UV) spectrum from the HPLC with a UV spectra library containing 2682 toxicologically relevant substances $^{9}$ did not show any other drugs in the plasma.

A polymerase chain reaction-restriction fragment polymorphism (PCR-RFLP) method $^{10}$ was used to genotype polymorphisms in the CYP2C8 gene. This showed the subject to be of the $2 \mathrm{C} 8 * 1$ (wild type) variant. The symptoms improved upon administration of diazepam (3mg stat dose) and intravenous fluids (0.18 Saline in $4.3 \%$ dextrose solution). She made an uneventful recovery and was discharged two days later. She remained well at follow up one week later.

\section{Case 2}

The subject was a 12 -year old, $35 \mathrm{~kg}$ female who participated in a clinical trial of antimalarial drugs. She presented with a four-day history of fever, chills, vomiting, abdominal pain and an axillary temperature of $39.4^{\circ} \mathrm{C}$. She denied intake of any drugs prior to presentation and her past medical history was unremarkable. On presentation, her blood pressure was, $110 \mathrm{mmHg}$, apex beat was palpable in the $5^{\text {th }}$ left intercostal space in the mid-clavicular line, she was not cyanosed, and there was no peripheral oedema.

Laboratory investigation showed $P$. falciparum parasitaemia of parasite density $69,654 / \mu \mathrm{L}$; haemoglobin, 12 $\mathrm{g} / \mathrm{dL}$; total white blood cell count, $5.7 \times 10 \% / \mathrm{L}$, and a neutrophil differential count of $64 \%$. Urine microscopy and culture, blood urea and serum electrolytes, and chest radiograph were normal. An initial electrocardiography (ECG) done as part of the clinical trial investigations showed sinus rhythm, with a ventricular rate of 103 beats per minute and a rate-corrected QT interval (QTc) of 395 ms. Amodiaquine (Camoquine ${ }^{\circledR}$; Pfizer, Dakar, Senegal), $10 \mathrm{mg} / \mathrm{kg}$ body weight, single oral daily dose, was administered under supervision for three days, with acetaminophen, $15 \mathrm{mg} / \mathrm{kg}$ body weight (one and a half tablets), three times daily. On the second day of treatment, a repeat blood smear (temperature $36.5^{\circ} \mathrm{C}$ ) showed $P$ falciparum asexual parasitaemia of $480 / \mu \mathrm{L}$. On auscultation on this day, a grade $2 / 6$ ejection systolic murmur, which was heard best in the $2^{\text {nd }}$ left intercostal space at the left sternal border, and which radiated towards the left shoulder, was audible. The blood film was negative on the third day of treatment, but the ECG-measured heart rate was 49 beats/min (axillary temperature was $36.5^{\circ} \mathrm{C}$ ). Echocardiography, which was done because of the audible heart murmur, reported "mild pulmonary stenosis".

DEAQ concentrations were $130 \mathrm{ng} / \mathrm{ml}, 110 \mathrm{ng} / \mathrm{ml}$, $38 \mathrm{ng} / \mathrm{ml}$, and $9 \mathrm{ng} / \mathrm{ml}$ in plasma samples taken $3,7,14$, and 28 days post-treatment. Plasma concentrations of bis-DEAQ, were $25 \mathrm{ng} / \mathrm{ml}, 10 \mathrm{ng} / \mathrm{ml}$ and $5 \mathrm{ng} / \mathrm{ml}$ in samples taken 7, 14 and 28 days post-treatment. The plasma concentrations of DEAQ and bis-DEAQ were both below the limit of quantification in plasma samples taken 33 and 47 days post-treatment. There was no detectable amodiaquine, DEAQ, or bis-DEAQ in the pre-treatment sample. The subject was homozygous for the $2 \mathrm{C} 8 * 1$ variant and further toxicological screening did not detect any other drugs in plasma, except acetaminophen. Bradycardia persisted through the next six weeks. She complained occasionally of easy fatigability, but there were no complaints of dizziness, chest pain, or shortness of breath. On the $84^{\text {th }}$ and $92^{\text {nd }}$ days after recruitment, a heart rate of 64 and 72 beats per minute respectively were recorded on the ECG. She has remained well on subsequent visits. 


\section{DISCUSSION}

There is little information on the possible mechanisms that may underlie amodiaquine-associated adverse effects, despite the relatively long history of use of this drug. Amodiaquine-associated dystonic reaction was first reported by Akindele, who suggested that this is an idiosyncratic reaction. ${ }^{4}$ Although the pharmacokinetics of amodiaquine is known to exhibit wide interindividual variation ${ }^{11}$, the finding of normal ${ }^{12}$ plasma DEAQ levels, despite reported intake of several fold the recommended therapeutic dose of amodiaquine in a subject with wild type CYP2C8, supports the assertion of idiosyncrasy.

The mechanism underlying amodiaquine-associated dystonic reactions may also be similar to that of chloroquine-associated dystonia, which has been linked to reduction in fore-brain catecholamine levels and inhibition of neuronal calcium uptake. ${ }^{13}$ This assertion could be supported in part, by the observed effectiveness and symptom reversal of the dystonia by diazepam: it has been proposed that stimulation of the benzodiazepine receptors coupled to the $\gamma$-amino butyric acid (GABA) receptors via the chloride ion channel in the central nervous system facilitate GABA transmission, with a consequent inhibitory effect on muscle hypertonia and tremors. Other possible mechanisms that may underlie amodiaquine-associated adverse effects could be related to, CYP1A1 or 1B1-mediated extrahepatic metabolism of amodiaquine ${ }^{3}$, or biotransformation to chemically reactive electrophilic quinoneimine metabolites which, by forming immunogenic complexes, may lead to organ-specific toxicity in susceptible individuals.

Sinus bradycardia, which may occur during fever resolution in malaria, has been reported after amodiaquine treatment in malaria patients with or without fever. ${ }^{14}$ Although falciparum malaria itself is known to be associated with electrophysiological changes in the heart - independent of antimalarial drug intake ${ }^{15}$, amodiaquine is known to slow cardiac conduction ${ }^{16,17}$, and to cause bradycardia, in animals. ${ }^{18}$ In the second subject described in this report, the first recording of bradycardia coincided with the time of expected peak cumulative plasma concentration of $\mathrm{DEAQ}^{19}$, strongly suggesting the possibility of a direct drug effect. The presence of the mild pulmonary stenosis may be a coincidental finding.

It is also possible that this underlying cardiac disorder - albeit mild and previously undiagnosed - could have altered the predisposition of the subject to adverse cardiovascular effects of amodiaquine. There are currently many reports of clinical trials involving amodiaquine, but few reports on amodiaquine-associated cardiovas- cular effects are available. It may, therefore, be important to pay particular attention to patients with underlying cardiovascular disease who are on treatment with amodiaquine-based regimens. It would be useful also, to include cardiac assessment in the post-marketing surveillance of amodiaquine-containing regimens. Further studies aimed at elucidating the mechanisms underlying these effects, especially within the context of the use of amodiaquine as a partner drug in combination therapy, would especially be desirable.

\section{ACKNOWLEDGEMENTS}

The study received financial support from the Danish Council for Development Research (RUF grant no. 91199). We thank Dr E. Oliviera of the National Cardiothoracic Centre Korle Bu Teaching Hospital, for the echocardiography.

\section{REFERENCES}

1. Hatton C.S., Peto T.E., Bunch C., Pasvol G., Russell S.J., Singer C.R., Edwards G. and Winstanley $P$. Frequency of severe neutropenia associated with amodiaquine prophylaxis against malaria. Lancet. 1986 Feb 22;1(8478):411-414.

2. Neftel K.A., Woodtly W., Schmid M., Frick P.G. and Fehr J. Amodiaquine induced agranulocytosis and liver damage. Br Med J (Clin Res Ed). 1986 Mar 15;292(6522):721-723.

3. Li X.Q., Bjorkman A., Andersson T.B., Ridderstrom M. and Masimirembwa C.M. Amodiaquine clearance and its metabolism to $\mathrm{N}$ desethylamodiaquine is mediated by CYP2C8: a new high affinity and turnover enzyme-specific probe substrate. J Pharmacol Exp Ther. 2002 Feb;300(2):399-407.

4. Akindele M.O. and Odejide A.O. Amodiaquineinduced involuntary movements. $\mathrm{Br}$ Med J. 1976 Jul 24;2(6029):214-215.

5. Kamagate M., Die-Kacou H., Balayssac E., Daubret P.T. and Yavo J.C. Oro-facial dyskinesias and amodiaquine. Therapie. 2004 Sep-Oct;59(5):565566.

6. Akpalu AK N.P., Dodoo ANO. Amodiaquineinduced dystonic reactions: case reports and implications for policy change in Ghana. Int J Risk Safety Med. 2005;17:1-4.

7. Lind D.E., Levi J.A. and Vincent P.C. Amodiaquine-induced agranulocytosis: toxic effect of amodiaquine in bone marrow cultures in vitro. $\mathrm{Br}$ Med J. 1973 Feb 24;1(5851):458-460.

8. Clarke J.B., Neftel K., Kitteringham N.R. and Park B.K. Detection of antidrug IgG antibodies in patients with adverse drug reactions to amodiaquine. Int Arch Allergy Appl Immunol. 1991;95(4):369375. 
9. Pragst F., Herzler, M, Herre, M, Erxleben, B-T, Rothe, M. UV spectra of toxic compounds. 2001; Berlin, Germany; 2001.

10. Cavaco I., Stromberg-Norklit J., Kaneko A., Msellem M.I., Dahoma M., Ribeiro V.L., Bjorkman A. and Gil J.P. CYP2C8 polymorphism frequencies among malaria patients in Zanzibar. Eur J Clin Pharmacol. 2005 Mar;61(1):15-18.

11. White N.J., Looareesuwan S., Edwards G., Phillips R.E., Karbwang J., Nicholl D.D., Bunch C. and Warrell D.A. Pharmacokinetics of intravenous amodiaquine. $\mathrm{Br} \quad J \quad$ Clin Pharmacol. 1987 Feb;23(2):127-135.

12. Aubouy A., Bakary M., Keundjian A., Mbomat B., Makita J.R., Migot-Nabias F., Cot M., Le Bras J. and Deloron P. Combination of drug level measurement and parasite genotyping data for improved assessment of amodiaquine and sulfadoxinepyrimethamine efficacies in treating Plasmodium falciparum malaria in Gabonese children. Antimicrob Agents Chemother. 2003 Jan;47(1):231-237.

13. Achumba J.I., Ette E.I., Thomas W.O. and Essien E.E. Chloroquine-induced acute dystonic reactions in the presence of metronidazole. Drug Intell Clin Pharm. 1988 Apr;22(4):308-310.

14. Ngouesse B., Basco L.K., Ringwald P., Keundjian A. and Blackett K.N. Cardiac effects of amodiaquine and sulfadoxine-pyrimethamine in ma- laria-infected African patients. Am J Trop Med Hyg. 2001 Dec;65(6):711-716.

15. vn Seidlein L., Jaffar S. and Greenwood B. Prolongation of the QTc interval in African children treated for falciparum malaria. Am J Trop Med Hyg. 1997 May;56(5):494-497.

16. Bose D. and Dresel P.E. Site of origin of bigeminal rhythms produced by amodiaquin in the dog. Am J Physiol. 1971 Jun;220(6):1866-1870.

17. Kirk B.W. and Dresel P.E. Effects of Amodiaquin and Quinidine on Cardiac Conduction. Can J Physiol Pharmacol. 1965 Jan;43:29-38.

18. Pandya K.H., Jindal M.N. and Kelkar V.V. Mechanism of amodiaquine-induced supersensitivity to catecholamines. Eur J Pharmacol. 1969;6(3):265-273.

19. Hombhanje F.W., Hwaihwanje I., Tsukahara T., Saruwatari J., Nakagawa M., Osawa H., Paniu M.M., Takahashi N., Lum J.K., Aumora B., Masta A., Sapuri M., Kobayakawa T., Kaneko A. and Ishizaki T. The disposition of oral amodiaquine in Papua New Guinean children with falciparum malaria. Br J Clin Pharmacol. 2005 Mar;59(3):298301. 